\title{
Surgery at Cranio-vertebral (CV) Junction: Our Experience of 32 Cases
}

\author{
FH CHOWDHURY ${ }^{a}$, MR HAQUE ${ }^{b}$, NKSM CHOWDHURYc $^{c}$, MS ISLAM ${ }^{\mathrm{d}}$, Z RAIHAN ${ }^{\mathrm{e}}$, MH SARKAR $^{\mathrm{f}}$
}

\begin{abstract}
Summary
Cranio vertebral (CV) junction is one of the critical sites for surgery. It's anatomy, physiological aspects and pathological involvement varies in a wide range of margins. Common problems are developmental anomalies, traumatic involvement, inflammatory, infective and neoplastic lesion. Management of these problems varies a lot from each other. Aim of the article is to overview the pathologies in this area and to study presentations, investigations, surgical procedures and results of these pathologies.
\end{abstract}

We prospectively analyzed 32 cases of Cranio-vertebral (CV) region surgery in the Department of Neurosurgery Dhaka Medical College Hospital and Mitford Hospital, Dhaka, from 2000 to 2008.

In our series, male and female ratio was 7.2:1. Pathologies were atlanto- axial dislocation (AAD), Chiari malformation

\section{Introduction}

Cranio vertebral (CV) junction is anatomically and functionally very complex zone. Anatomical variations of neurovascular and skeletal components in this site are quite common. Here, many types of developmental anomalies, traumatic fracture\& dislocation, inflammatory, infective and neoplastic lesions are common lesions. Management of these problems varies

a. Dr. Forhad Hossain Chowdhury, FCPS, Neurosurgeon, Department of Neurosurgery, Dhaka Medical College, Dhaka.

b. Dr. Md. Raziul Haque, FCPS, Associate Professor, Department of Neurosurgery, Dhaka Medical College, Dhaka.

c. Dr. SM Noman Khaled Chowdhury, MS, Neurosurgeon,Dhaka Medical College,Dhaka.

d. Dr. Md. Shafiqul Islam, Ph.D, Neurosurgeon, Department of Neurosurgery, Dhaka Medical College, Dhaka.

e. Dr. Zahid Raihan, MS, Neurosurgeon, Department of Neurosurgery, Dhaka Medical College, Dhaka.

f. Dr. Mainul Haque Sarkar, MS,, Professor, Department of Neurosurgery, Dhaka Medical College, Dhaka.

Address of correspondence to: Dr. Forhad Hossain Chowdhury, FCPS, Neurosurgeon, Department of Neurosurgery, Dhaka Medical College, Dhaka. Bangladesh. e-mail- forhadchowdhury@yahoo.com Received: 29 September, 2009

Accepted: 2 November, 2010 type -I, schwannoma, meningioma, hydatid cyst and tuberculosis. Common clinical findings were- neck pain, quadriparesis, quadriplegia, hand atrophy, autonomic dysfunction and hypertension. Various types of surgical procedures were done in this series according to the pathology. Death was in 01 case, neurological deterioration seen in one case, 2 cases were neurologically stable and 28 cases (87.5\%) improved neurologically where one was non useful improvement(Frankel grade-C).

Complete pre operative radiological study is a very important adjunct for a successful surgical result. Proper evaluation of patients with selection of appropriate surgical procedures along with safe surgical techniques are the necessary things for successful surgery in this area.

(J Bangladesh Coll Phys Surg 2011; 29: 78-84)

a lot from each one another. Therefore without adequate background knowledge and surgical skill, surgery at this site is dangerous. Proper anatomical, physiological, pathological, radiological knowledge and surgical skill is preliminary things before surgical visit in this critical site. Aim of the article is to overview the surgical pathologies in this area along with their clinical presentations, investigations, surgical procedures \& results as well as to share our experiences to our colleagues.

\section{Methods:}

We prospectively analyzed 32 cases of Cranio-vertebral (CV) region surgery in the Department of Neurosurgery Dhaka Medical College Hospital and Mitford Hospital, Dhaka, from January'2000 to July'2008.The complete history was taken regarding neck pain, weakness, sensory dysfunction and autonomic dysfunction. Then neurological findings of preoperative and postoperative last follow up were recorded for analysis. Neurological status was assessed by Frankel grading system. Improved was defined as improved neurological status at the last follow-up compared with the preoperative neurological status. Average duration of follow up is 11.4 months (range - 4.5 months to 96 months) 


\section{Observations and Results:}

Total No of cases-32. Sex- male: 28(87.5\%) and female: 04(12.5\%). Average age-37.27 years, range-20 to 65 years.

\section{Pathologies in this area were-}

Atlanto- axial dislocation (AAD)- 19 cases(59.3\%)

*traumatic-05 cases (15.62\%)

*developmental-07 cases (21.87\%)

*spontaneous-06 cases (18.75\%)

*Psoriatic arthritis-01case (3.12\%)

Chiari malformation type -I: 04 cases (12.48\%; Table-

2,case no-1,2,3 \& 4)

Schwannoma- 04 cases (12.5\%; Table-2, case no-7,8,9 \& 10)

Meningioma- 02 cases (6.25\%; Table-2, case no- 11 \&12)

Hydatid cyst- 01 case (3.37\%; Table-2, case no-13)

Tuberculosis- 02 cases (6.25\%; Table-2, case no-5 \& 6)

Clinical features were-

Neck pain- 24 cases (75\%),

Quadriparesis-27cases (84.3\%)

Quadriplegia-04 cases (12.5\%)

Hand atrophy-04 cases (12.5\%)

Autonomic dysfunction-05 cases (15.62\%)

Hypertension-01 case (3.12\%).

Features of skeletal dysplasia-04 cases (12.5\%)

Respiratory difficulty-02 cases (6.25\%)

Investigations done in these patients-

Plain x-ray anterior-posterior \& neutral lateral view were done in all cases (100\%); Flexion \& extension lateral view and open mouth views in 26 cases (81.25\%). MRI done in all 32 cases (100\%). CT scan done in 07 cases (21.87\%).3-D CT scan was done in 02 cases (6.25\%).

Operative procedures done in these cases were-

Reduction and bilateral C1C2 transarticular screw fixation with fusion by bone grafting-09 cases (28.12\%;Table-1,case no-1,2,3,4,12,13,16,17\&19)

Reduction and unilateral C1C2 transarticular screw fixation with fusion by bone grafting-01 case (3.12\%; Table-2, case no.-6).

Sublaminar wiring and occipitocervical fusion-2 cases (6.25\%; Table-1,case no-10 \&11).
Stabilization by U loop and wire followed by occipitocervical fusion-02 cases (6.25\%;

Table-1, case no-14\&18)

Posterior fossa decompression with removal of C1 posterior arch and duraplasty-04 cases (12.5\%; Table2, case no-1,2,3 \& 4)

Removal of tumour/cyst through posterior/posteriorlateral approach-07 cases (21.86\%; Table-2, case no$7,8,9,10,11 \& 13)$.

Posterior stabilization by loop/wiring/transarticular screw + occipito-cervical/atlanto-axial fusion and transoral decompression-03 cases[9.37\%; Table-1,case no-1,5\&15(Figure-1\&2)]

Peroperative reduction and C1C2 lateral mass screw\& plate stabilization and fusion-03 cases (9.37\%; Table1, case no-7,8 \& 9).

Decompression by removing posterior margin of foramen of magnum with preparation of $\mathrm{C} 1$ from occiput followed by U loop-wire stabilization and bony fusion between prepared $\mathrm{C} 1$ and $\mathrm{C} 2$ along with transoral decompression -one case(3.12\%;Table-1,case no-6).

Transoral drainage of abscess-01 case (3.12\%; Table2, case no-5).

\section{Complications -}

Death-01 case (3.12\%; Table-1, case no-10)

Transient CSF fistula-01 case (3.12\%; Table-2, case no-9)

Palatal incompetence (Following transoral decompression, improved after 06 months)-01case (3.12\%; Table1, case no-15)

Persistent neck pain-03 cases (9.37\%; Table-1, case no1, 5 \&17)

Persistent spasticity-02 cases (6.25\%; Table-1, case no$1 \& 5)$

Neurological deterioration-01 case (3.12\%; Table-2, case no-9)

Break of one Transarticular C1C2 screw followed by neurological deterioration-01case (3.12\%; Table-1, case no-1; Figure-3 F). Here neurological stability was made by transoral decompression)

Results of CV junction surgery-

Complete or near complete neurological recovery (Frankel grade-E +/- persistent hand atrophy)-14 cases (43.75\%) 
Improved but not normal neurostatus-

Frankel grade-C (not useful)-01 case (3.12\%; Table-2, case no-4)

Frankel grade-D (useful)-13 cases (40.62\%)

Stable (peroperative and postoperative Frankel gradeE)-02 cases (6.5\%; Table-1, case no-13 and Table-2, case no-5)
Deterioration-01case (3.12\%; Table-1, case no-9, preoperative Frankel grade-D, postoperative grade-C)

Death-01 case (3.12\%; Table-1, case no-10).

In table -1 and table-2 clinical profile, surgical procedures and outcome of $\mathrm{CV}$ junction surgery cases are shown.

Table-1

Age, sex and pathological profile as well as pre and post surgical neurological status in $A A D$

\begin{tabular}{|c|c|c|c|c|}
\hline $\begin{array}{l}\text { No \& } \\
\text { sex }\end{array}$ & $\begin{array}{l}\text { Age } \\
\text { (yrs) }\end{array}$ & Diagnosis & $\begin{array}{l}\text { Preop } \\
\text { Frankel } \\
\text { Grade } \\
\end{array}$ & Final outcome \& Frankel Grade \\
\hline 1.M & 45 & Traumatic AAD & (A) & $\begin{array}{l}\text { Improved but can just walk with support; persistent } \\
\text { spasticity\& pain (D-) }\end{array}$ \\
\hline 2.M & 40 & $\mathrm{AAD}$ & (D) & Full recovery(E) \\
\hline 3.M & 38 & AAD & (D) & Full recovery(E) \\
\hline 4.M & 26 & Tr.AAD \&Odontoid \# & (C) & Improved(D) \\
\hline 5.M & 65 & BI with cervical C3-4 disc prolapse & (C) & Improved but persistant spasticity \& pain (D) \\
\hline 6.M & 36 & \multicolumn{2}{|c|}{ Fixed AAD\& BI with occipitalization of C1(C) } & Improved.(D) \\
\hline 7.M & 35 & Fixed AAD & (C) & Improved(D) \\
\hline 8.M & 43 & Platybasia with BI with syrinx & (C) & Improved( Grade-D ) \\
\hline 9.M & 28 & Sk. dysplasia with AAD & (D) & $\begin{array}{l}\text { Immediate post operatively patient deteriorated then } \\
\text { improved but not upto preoperative state.(C) }\end{array}$ \\
\hline $10 \mathrm{M}$ & 56 & AAD & (A) & $\begin{array}{l}\text { Respiration stabilized,but no neurological recovery, } \\
\text { later expired. }\end{array}$ \\
\hline $11 \mathrm{M}$ & 45 & AAD & (C) & Improved but restricted neck movements(D) \\
\hline 12.M & 28 & Tr. dens \# with AAD & (C) & Complete recovery(E) \\
\hline 13.M & 39 & $\mathrm{AAD}$ & (E) & Neck pain gone(E) \\
\hline 14.M & 21 & Sk. dysplasia with AAD & (D) & Improved except incontinence of urine(E) \\
\hline 15.M & 25 & SkDysplasia with HTN with AAD Fixed & (D) & $\begin{array}{l}\text { Improved completely but palatal/nasal regurgitation, } \\
\text { improved later(E) }\end{array}$ \\
\hline 16.M & 44 & AAD & (D) & Improved(E) \\
\hline 17.M & 34 & AAD Tr. & (C) & Improved(D) \\
\hline 18.F & 41 & AAD with Psoriatic arthritis & (D) & Improved with persisted neck pain(E) \\
\hline 19..M & 55 & $\operatorname{Tr} \mathrm{AAD}$ &.$(\mathrm{C})$ & Improved(D) \\
\hline
\end{tabular}

[No-Number, yrs-years, C/F-clinical features, M-male, F-female, Tr-traumatic, Preop-Preoperative,AAD-atlantoaxial dislocation, BI-basillar invagination, Sk-skeletal, \#-fracture, HTN-hypertension, Frankel grading-A,B,C,D\&F]. 


\section{Table-II}

Age, sex and pathological profile as well as pre and post surgical neurological status in other pathologies of $C V$ junction (excluding $A A D)$

\begin{tabular}{|c|c|c|c|c|}
\hline $\begin{array}{l}\text { N\& } \\
\text { sex }\end{array}$ & $\begin{array}{l}\text { Age } \\
\text { (yrs) }\end{array}$ & & $\begin{array}{c}\text { Preop } \\
\text { Frankel } \\
\text { grade } \\
\end{array}$ & Final outcome \& Frankel grade \\
\hline 1.M & 42 & Chiari -1 & $(\mathrm{C})$ & Improved except hand atrophy(D) \\
\hline 2.F & 36 & Chiari 1 with syrinx & (D) & Improved(E) \\
\hline 3.M & 20 & Chiari-1 & (C) & Improved except hand atrophy(D) \\
\hline 4.M & 28 & Chiari-1 & $(\mathrm{B}+)$ & Improved (C) \\
\hline 5.M & 25 & AAJ TB with retropharyngeal abscess & s $(\mathrm{E})$ & Improved(E) \\
\hline 6.M & 38 & Tubercular AAD & (D) & Complete recovery(E) \\
\hline 7.M & 35 & FM and high cervical Schwannoma & (C) & Complete recovery(E) \\
\hline 8.M & 27 & FM Schwannoma & $(\mathrm{C})$ & Improved(Postop. CSF fistula)(D) \\
\hline 9.M & 39 & C1C2 schwannoma & (D) & Complete recovery(E) \\
\hline 10.F & 44 & FM and high cervical schwannoma & (D) & Complete recovery(E) \\
\hline $1 \mathrm{M}$ & 30 & FM and high cervical meningioma & (C) & Improved(D) \\
\hline $1 \mathrm{M}$ & 50 & C1C2 meningioma & (D) & Complete recovery(E) \\
\hline 13.F & 21 & C1C2 hydatid cyst & (B) & $\begin{array}{l}\text { Recurrence of cyst that regressed with } \\
\text { albandazole(E) }\end{array}$ \\
\hline
\end{tabular}

[No-Number, yrs-years, C/F-clinical features, M-male, F-female, Preop-Preoperative ,AAD-atlantoaxial dislocation,AAJatlantoaxial joint, FM-foramen magnum,TB-tuberculosis, Frankel grading-A,B,C,D\&F].

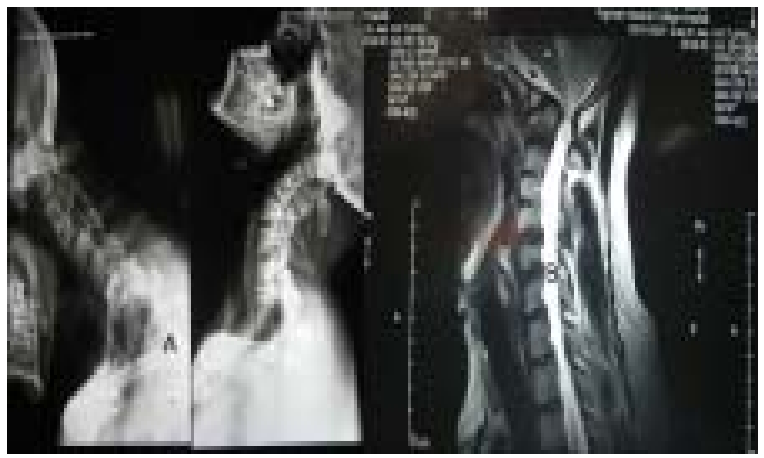

Fig.-1: A-x-ray cervical spine flexion \& extension view, $B-M R I$ saggital section T1W image showing craniovertebral anomaly with irreducible atlanto-axial dislocation $(A A D)$

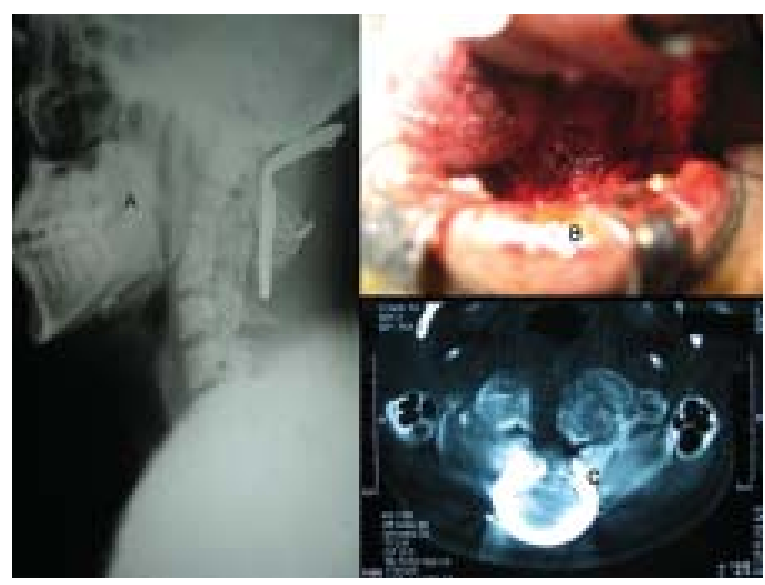

Fig.-2: A-x-ray after posterior stabilization, $B$ peroperative view of closure of pharyngeal wound after transoral odontoidectomy, C-CT Scan of CV junction axial view showing absence of dens. 


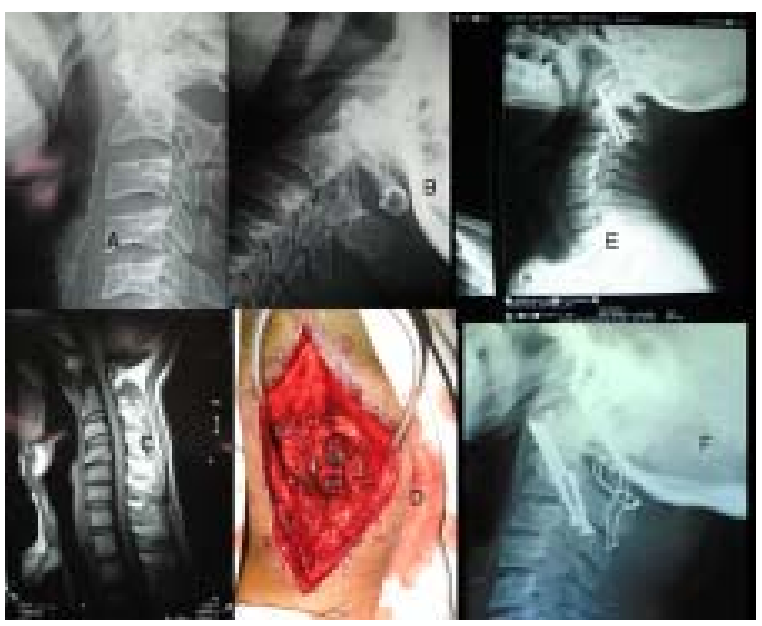

Fig.-3: A-X-ray controlled flexion lateral view, $B$-X-ray extension lateral view, $C-M R I T 1 W$ saggital image of cervical spine showing reducible $A A D$. D-peroperative picture of c1 c2 transarticular screw fixation. Epostoperative $x$-ray showing bilateral c1c2 transarticular screw. $F$ - $X$-ray showing hardware failure in a different case(broken one screw)

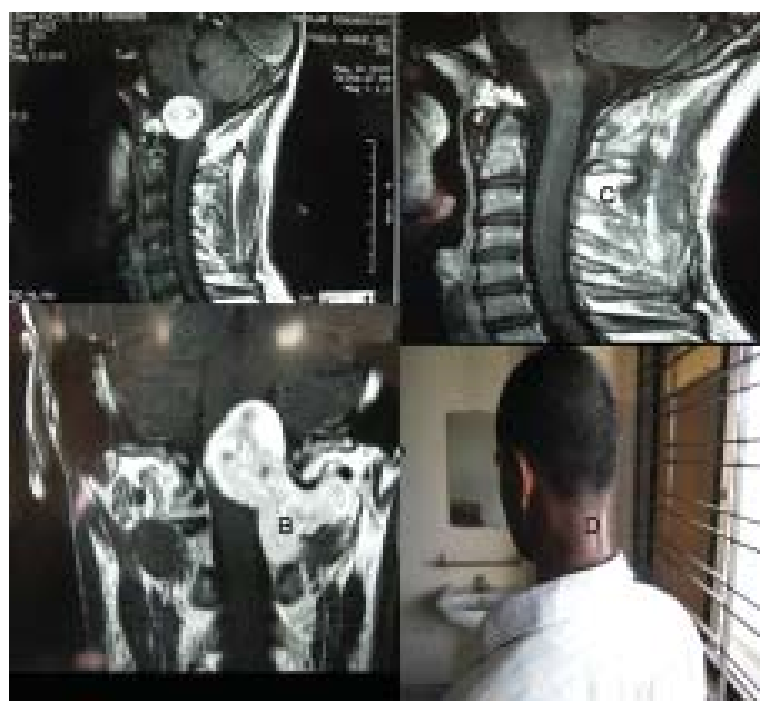

Fig.-5: A-MRI saggital section T1W image, B-MRI coronal section $T 1 W$ image of $C V$ junction showing schwannoma. C-Postoperative MRI of CV junction

\section{Discussion:}

Various types of abnormalities can affect ${ }^{1}$ cranio vertebral junction. Common pathologies includedevelopmental anomalies i.e. atlanto-axial dislocation (AAD), basilar invagination (BI), Chiari malformation, syringomyelia etc; traumatic i.e. AAD, fracture of $\mathrm{C} 1$,

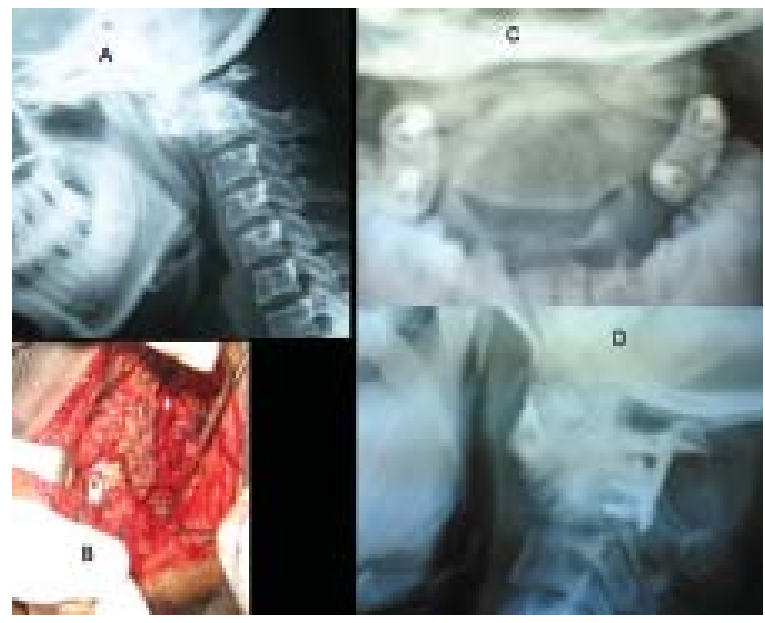

Fig.-4:A-X-ray $C V$ junction lateral view showing non reducible $A A D, B$-peroperative picture of $C 1 C 2$ lateral mass plate and screw fixation, $C$-x-ray $C V$ junction open mouth view showing lateral mass plate and screw, $D$ $X$-ray CV junction lateral view showing C1C2 lateral mass plate and screw in non reducible $A A D$ with bone fusion.

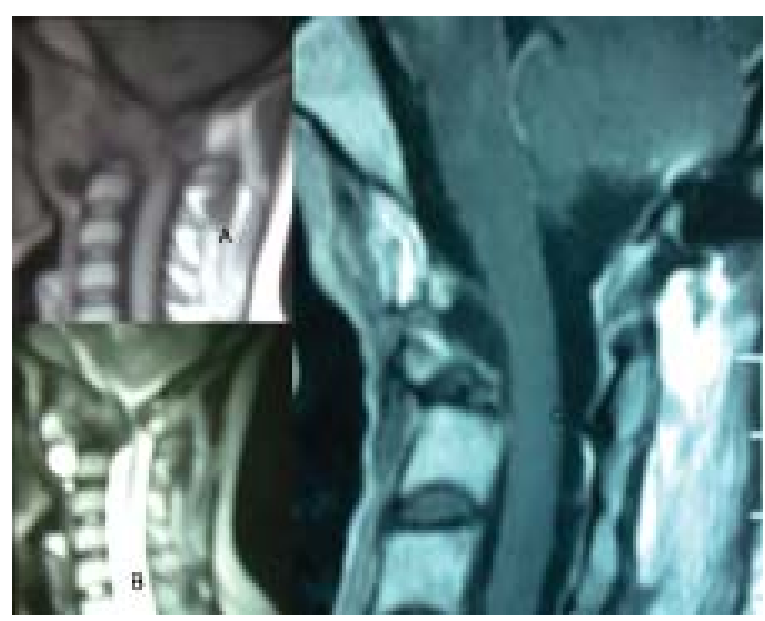

Fig.-6: A-MRI of $C V$ junction saggital section $T 1 W$ image, B-MRI of CV junction saggital section $T 2 W$ image showing multiple cystic lesion compressing cervico- medullary junction. C-Postoperative MRI saggital section $T 1 W$ image showing no residual cyst.

C2, odontoid fracture etc; inflammatory-rheumatoid arthritis; infective-tuberculosis; neoplasticschwannoma, meningioma, cordoma, bony tumour etc. $1,2,3,4,5,6,7,8,9,10,11,12$ In our study, we can find the similar picture. Here we found a very rare condition that is hydatid cyst (Table-2,case no-13). This was a 
known case of hydatid cyst and she underwent surgery at $\mathrm{CV}$ junction in abroad 1 year back; after $1^{\text {st }}$ operation she improved but later she developed quadriplegia. In our another case (Table-1,case no-19), we found AAD associated with psoriatic arthritis. Young people are commonly affected by CV junction pathologies. In this series common age is 25 to $45 y$ years. Common mode of presentation is history of trauma, neck pain, features of myelopathy i.e .quadriparesis or quadriplegia, hand muscle atrophy, autonomic dysfunction etc. ${ }^{1,2,3,4,5,8 \text {, }}$ Plain x-ray is very important to see bony alignment ,AAD dislocation and its reducibility. CT scan gives much better information than plain $\mathrm{x}$-ray but usually done when $\mathrm{x}$-ray picture is not clear. ${ }^{2,3,4,5}$ We have done plain X-ray in all cases but CT scan in 04 cases only. MRI is essential to see neural pathology and other soft tissue pathology. We have done MRI in all cases. We also used per operative radio-imaging to see the reduction, alignment of atlanto-axial joint $\&$ bones and also to see the tract of screw.

We put three traumatic $\mathrm{AAD}$ patient under tong traction for a period of 7-15 days. Surgical procedures varies according to the pathology in CV junction. 2,4,5,7

When AAD is reducible assessed by preoperative flexion and extension lateral view x-ray and lateral masses of C1 and C2 are intact (not destroyed by pathological process), bilateral transarticular lateral mass screw fixation is done. Transarticular screw fixation is one of the important method in the treatment of craniocervical instability. ${ }^{13,14,15}$ It gives immediate stability to $\mathrm{C}-\mathrm{V}$ junction and patient can be mobilized on immediate post operative period. Peroperative mal tracking of screw with vertebral artery injury or spinal cord damage which are potentially dangerous complications. ${ }^{13,14,15}$ Restriction of neck mobility is not so prominent here. To prevent long term hardware failure usually C1 C2 posterior bony fusion done along with the screw. Reduction and bilateral C1C2 transarticular screw fixation with fusion by bone grafting done in 09cases in our series (Figure-3). Reduction \& unilateral C1C2 transarticular screw fixation with fusion by bone grafting done in 01 case due to destruction of opposite lateral mass by tubercular lesion. In one of our cases one sided screw was broken six month after operation (Table-1,case no-1;Figure-3F) and there was neurological deterioration with severe neck pain, for which we have to go for transoral odontoidectomy; patient improved after anterior decompression.

Posterior fossa decompression with removal of C1 posterior arch +/-C2 laminectomy and duraplasty is the usual treatment in type-I Chiari malformation. ${ }^{16}$ If syrinx is associated with the malformation some advocate syringosubarachnoid shunt. We did not perform any shunt in presence of syrinx.

When per operative reduction of AAD is not possible or transarticular screw fixation or lateral mass screw fixation is not possible then posterior stabilization by loop/wiring + occipito-cervical/atlanto-axial fusion with

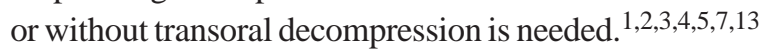
After posterior stabilization we did transoral decompression in-03 cases.

C1C2 lateral mass screw\& plate stabilization and fusion is one of the important techniques described by Goel et al, is used for treating reducible AAD or reducible basilar invagination and other craniovertebral pathologies. ${ }^{17,18}$ We used this technique in three (9.09\%) cases of AAD. In one case we failed to reduce $\mathrm{AAD}$ (only partial reduction was possible peroperatively by traction and effort of joint distraction) where stabilization was done by C1C2 lateral mass plate and screw with bone fusion and advised for transoral decompression on separate occasion. Postoperatively patient improved neurologically and refused second operation (Figure-4).

In one case we found BI with occipitalization of C1 and morphological dysgenesis and hyperplasia of C2.In such a case options are- preparation of $\mathrm{C} 1$ from occiput +/- decompression by removing posterior margin of foramen of magnum followed by occipito-axial fusion/ C1-C2 lateral mass plate \& screw fixation with or without transoral decompression. ${ }^{19,20}$ Here decompression by removing posterior margin of foramen of magnum with preparation of $\mathrm{C} 1$ from occiput followed by U loop-wire stabilization and bony fusion between prepared $\mathrm{C} 1$ and $\mathrm{C} 2$ was done.In this case we went for transoral odontoidectomy on a separate setting.

Tumors in this area is usually removed through posterior, posterolateral, lateral or far lateral approaches. ${ }^{8,9,10,11,12}$ We used posterior \& posterior-lateral approach only (Figure-5).

In the case of hydatid cyst we removed the cysts through posterior approach and she recovered, completely after 
8 months cyst recur with some neurological deterioration, we put her on anti helminthic; cyst disappeared and she recovered again(Figure-6). She got married 2 months back but she is still on albandazole.

In our series one patient expired from severe high cervical spinal injury with respiratory distress before operation. Another patient expired three months after operation from complication of quadriplegia (bedsore, urinary tract infection and respiratory tract infection) who had quadriplegia with respiratory distress preoperatively. Postoperatively respiration was stable but there was no neurological improvement.

One patient deteriorated immediate postoperatively who later improved but not up to preoperative state. This was due to iatrogenic damage. In one case of $\mathrm{CV}$ junction schwannoma we faced post operative CSF fistula that was managed by lumbar drain.

The ultimate result of CV junction surgery is in favour of surgeon when appropriately chosen surgical technique is applied by a safe surgeon. ${ }^{13}$ The rate of post surgical success varies according to pathologies along with severity \& duration of neurodeficit . In our series the neurological improvement was $93.75 \%$ (in spite of improvement one patient was non ambulant), deterioration in 3.12\% and death in 3.12\%.

\section{Conclusion:}

Surgery at CV junction is a very challenging task even for an experienced skullbase surgeon. Proper anatomical, physiological, pathological, radiological and surgical knowledge (i.e. Proper evaluation of patients with proper selection of surgical procedures along with safe surgical techniques) is essential for managing these pathologies in this surgically complex site.

\section{References:}

1. Greenberg MS: Spine and spinal cord. In Greenberg MS(ed): Handbook of Neurosurgery, $5^{\text {th }}$ ed. New York:Theim,2001,pp 285-351

2. VanGilder JC, Menezes AH, Dolan KD: Craniovertebral junction abnormalities. Mt Kisco, NY: Futura Publishing Company,1987.

3. Menezes Ah, VanGlider JC: Platybasia, basilar invagination and cranial settling. In Apuzzu MLJ (ed):Brain surgery complication, Avoidance and Management. NewYork: Churchill Livingstone,1993 pp 2029-2049.
4. Menezes AH, VanGlider JC: Anomalies of craniovertebral junction. In Youmans JR (ed): Neurological surgery, $3^{\text {rd }}$ ed. Philadelphia: Wb Saunders,1990, pp 1359-1420.

5. Menezes AH: Craniovertebral junction. In Albright AG, Pollock EF, Addision FD (eds): Principles and Practices of Paediatric Neurosurgery. New York:Theim,1999,pp 363-386.

6. VanGilder JC, Menezes AH: Craniovertebral junction abnormalities. In Willkins RH, Rengachery S (eds): Neurosurgery. New York: McGraw Hill,1996,pp 3587-3591.

7. Menezes AH: Surgical approaches to craniovertebral junction. In Weinstein SL,(ed):Pediatric Spine: Principles and Practice. New York: Raven Press, 1994,pp 1311-1327.

8. Menezes AH, Traynelis VC :Tumors of craniovertebral junction. In Youmans J (ed) Neurological Surgery. Philadelphia, WB Saundeas,1995,pp 3041-3072.

9. Meyer FB, Ebersold MJ, Reese DF: Benign tumors of foramen magnum. J Neurosurg 61:136-142,1984.

10. George, Lot G, Boissonnet H: Meningioma of the foramen magnum: A series of 40 cases. Surg Neurol 47:371-379,1997.

11. Arnaunotovic KI, Al-Mefty O ,Husain M: Ventral foramen magnum meningiomas. J Neurosurg 92:71-80,200.

12. Menezes AH: Tumors of the craniovertebral junction. In Menezes AH, Sonntag VH(eds): Principles of Spinal Surgery. New York,McGraw-Hill,1996,pp 1335-1353.

13. VanGilder JC, Menezes AH: Craniovertebral abnormalities and their Neurosurgical management.In Schmidek HH, Roberts DW (eds): Schmidek \& Sweet Operative Neurosurgical techniques:Indications, Methodes and Results, $5^{\text {th }}$ ed Vol-II: Philadelphia, Saunders,2006,pp 17171728.

14. Haid RW.C1-C2 Transarticular Screw Fixation: Technical Aspects.Neurosurg 2001;49:71-74.

15. Haid RW, Subach BR, McLaughlin MR, Rodts GE, Wahlig JB.C1-C2 Transarticular Screw Fixation for Atlantaxial INstibility: A six-year experience.Neurosurg2001;49:65-70.

16. Greenberg MS: Developmental anomalies. In Greenberg MS(ed): Handbook of Neurosurgery, $5^{\text {th }}$ ed. New York: Theim, 2001, pp 135-163.

17. Goel A, Laheri V. Plate and screw fixation for atlanto axial subluxation. Acta Neurochir (Wien) 994;129:47-53.

18. Goel A, Desai K, mazumder D. Atlanto axial fixation using plate and screw method: a report of 160 treated patients. Neurosurg 2002; 51:1351-1356.

19. Jain VK, Takayasu M, Singh S, Chharbra DK, Sugita K. Occipital-axis posterior wiring and fusion for atlantoaxial dislocation associated occipitalization of atlas: Technical note. J Neurosurg 1993;79:142-4.

20. Goel A, Kulkarni AG. Mobile and reducible atlantoaxial dislocation in presence of occipitalized atlas: report on treatment of eight cases by direct lateral mass plate and screw fixation. Spine 2004; 29: E520-3. 